\title{
DESIGNACIONES DE RASGOS FÍSICOS PERSONALES EN EL HABLA DE LA CIUDAD DE MÉXICO
}

\author{
I. Características corporales
}

1) Fealdad y defectos físicos

2) Belleza

3) Edäd

\section{VESTIDO Y PRESENTACIÓN}

1) Desaliño

2) Elegancia y su exageración

Las expresiones que aquí reunimos pertenecen todas al lenguaje que se habla hoy en la Ciudad de México. No sólo atendemos a lo típico y exclusivamente mexicano; incluímos términos empleados también en otros países de habla hispana, señalándolos con asterisco cuando sabemos que tienen en otro lugar el mismo sentido que aquí les damos' ${ }^{1}$.

Hasta donde ha sido posible, hemos precisado el matiz afectivo de los términos (o la ausencia de él) y el grado de su divulgación. Quedan excluídas desde luego las designaciones que sólo emplea un grupo limitado de personas (caló, jergas profesionales, etc.). Todos los vocablos y giros que citamos gozan de cierta popularidad (an-

${ }^{1}$ Se citan entre paréntesis los diccionarios en que figura la palabra o el giro con el mismo significado, de acuerdo con las siguientes abreviaturas: RD (=Feliz Ramos i Duarte, Diccionario de mejicanismos. Colección de locucio. nes $i$ frases viciosas, Méjico, 1895); I (=Joaquín García ICAzbalceta, Vocabulario de mexicanismos, México, 1899); RA (=Darío Rubio, La anarquía del lenguaje en la América española, México, 1925); RR (=DARío Rubio, Estudios paremiológicos. Refranes, proverbios y dichos y dicharachos mexicanos, 2 a ed., México, 1940); S (=Francisco J. Santamaría, Diccionario general de americanismos, México, 1942); M (=Augusto MALARET, Diccionario de americanismos, $3^{\text {a }}$ ed., Buenos Aires, 1946).

Además se han tomado citas de las siguientes obras: Mariano Azuela, la luciérnaga, Madrid-Barcelona, 1932; Las tribulaciones de una familia décente, 2ạ ed., México, 1938; Nueva burguesia, Buenos Aires, 1941; Ángel DE Campo, Pueblo y canto, México, 1939 (Biblioteca del Estudiante Universitario, vol. IX); Rafael Delgado, la Calandria, México, 1931; Felipe García Arroyo, El sol sale para todos, México, 1948; Rubén Salazar Mallén, Páramo, México, 1944. 
tigua o reciente); la mayoría de ellos se emplea en la conversación familiar y en la callejera, no en el trato cortés ni en el lenguaje literario. Por supuesto, su grado de difusión no es siempre igual: cualquier habitante de la ciudad conoce y emplea la palabra chaparro, pero no todos dirán es un sotaco, y muchos no habrán oído nunca es un reintegro; en la mayoría de los casos nos ha sido imposible definir exactamente el grupo humano que emplea de preferencia una expresión: cualquier intento de deslinde preciso estaba condenado de antemano a la arbitrariedad.

Al lado de los adjetivos incluímos sustantivos, verbos y frases coloquiales que sirven para calificar. Al citar frases se han puesto entre paréntesis los elementos que no siempre se usan: está hecho un judas (tronado); cuando alguna de sus palabras suele sustituirse por otra análoga, se $\epsilon$ mplea la siguiente forma: piernas (o patas) de chorro de atole (o de chorro de leche).

Se dejaron fuera las expresiones demasiado generales, como padre, que además de calificar a la persona hermosa, se aplica a toda cosa excelente, o como amolado, que no sólo se refiere al individuo físicamente desmedrado, sino también al que está en malas condiciones económicas, morales, etc.

El índice aclarará los aspectos que no siempre se exponen en el texto: si la palabra es adjetivo o sustantivo y con qué verbos se usa comúnmente.

\section{CARACTERÍSTICAS CORPORALES}

\section{1) Fealdad y Defectos físicos}

§ 1.-De la persona poco a tractiva, además de ${ }^{*} f e a$, * feisima, se dice que es o está fiera (RD, I) o fierisima ("Las niñas, a pesar de ser tan fieritas, estaban muy aseadas y bien vestidas", INCLÁN, I, 253), y también *feróstica. En ocasiones se dice que es un tepocate (S) o atepocate a $^{2}$ un ${ }^{*}$ macaco ${ }^{3}$. Expresiones corrientes: es fea con $F$ de ferrocarril, o con $F$ de foco fundido, y, más vulgarmente, con $F$ de fundillo (de fraile franciscano); es más fea que pegarle a Dios (RR, II, 154) o (menos usado) más fea que una noche oscura (R R, ibid.).

$\S$ 2.-Términos generales y descriptivos para designar al individuo d elga do son *delgado y *flaco; para el raquítico, *enclenque. Hay una serie de designaciones más expresivas, más teñidas de burla, desprecio o compasión: *enteco o *entecado (más raro), *encanijado (S), *esquelético, *espiritifláutico, *escuchimizado (me-

'Atepocate es en México 'renacuajo'. Según M, tepocate significa 'rechoncho'.

${ }^{3}$ Cf. la novela Concha Bretón de Mauricio Magdaleno, donde constantemente se designa de ese modo a una mujer fea. 
nos usual), *tilico (S, M) ${ }^{4}$, ñango (RD, S, M) o ñengo (RD Supl., S) charico (S, M) (menos frecuente). También se dice que es (o está hecho) un charal $(\mathrm{I}, \mathrm{S})^{6}$, un palillo, un ${ }^{*}$ esqueleto, un esqueleto rumbero $^{\top}$, un ${ }^{*}$ costal de huesos. A la mujer, en especial, la llaman *espátula, *escoba vestida, tabla vestida, (vieja) momia, culebra guajira y, con más burla, campeona de natación (porque "nada por delante y nada por detrás"). Otras expresiones humorísticas (para ambos sexos): ya vuela o está que vuela, es (o parecé) un chiflido, (si se pone) de perfil no se ve (o no se distingue), es un anuncio del paludismo, parece * gato de azotea (I, S) ("Está la pobre tan descolorida y flaca que parece gato de azotea", FERNÁndez DE LIZARDI, La Quijotita y su prima, I; citado por I).

La persona (o cosa) frági l y delicada parece * de alfeñique o está de mirame y no me toques $(\mathrm{S})$.

\$3--El fla co y a l to se designa comúnmente con los términos descriptivos *espigado, *esmirriado, *desmirriado o ismirriado; si además tiene las piernas muy largas, le dicen ${ }^{*}$ zancón $(\mathrm{S})^{8}$. Apodos para los altos y flacos son: la Percha, la Garrocha, el Kilómetro parado ${ }^{9}$.

Al hombre muy a $1 \mathrm{t}$ o suelen llamarlo -además de *alto, *altote, * grandote, * gigante y *gigantón-largotón, labregón ("está tamaño labregón”), bigardón ${ }^{10}$, kilométrico, y, humorísticamente, inspector de azoteas (o de alambres, o de postes) ${ }^{11}$; también se dice que se le ocupa para sacudir techos.

$\S 4$. - $^{*}$ Gordo es quizá el único término valorativamente neutral aplicado al hombre grueso y barrigudo. Las demás designaciones suponen casi siempre en quien las emplea una mayor carga afectiva: *gordinflón, *barrigón, *panzón, *tripón ${ }^{12},{ }^{*}$ tripudo, *timbón (RD, S, M) ${ }^{13}$, *botijón (S); también: es un (o muy) botijas, un *tonel, un *barril, un mantecas, un mantequillas, una llanta [='neu-

'RD: 'abultado'.

"Cf. en RD nango 'tonto, necio'.

'Charal es un pez mexicano muy pequeño (cf. Dicc. Acad.).

' Rumbero $=$ 'que baila la rumba'.

\& Véase el $\S 19$.

- Parado = 'de pie'.

${ }^{10}$ Labregón y bigardón se aplican también y ante todo al 'hombre joven y fuerte que no trabaja' (I,S).

11 Véase el $\S 5$.

12 Tripón, según $\mathrm{S}$, significa en varios lugares de la República, 'chiquillo, muchacho de poca edad'; según $M$, es 'chivo pequeño, cría'.

${ }^{13}$ Timba = 'barriga abultada' en México, Centroamérica, Santo Domingo y Venezuela (S, M). 
mático'], una tonina ${ }^{14}$ o un toni. Más ofensivas son las designaciones de la mujer gorda: *jamona, (vieja) sebosa (gorda y sucia). Del barrigudo se dice también que tiene panza de (o parece) pulquero ${ }^{15}$ o panza de tambora, que se dejó la panza (sobre el modelo de: "se dejó el bigote"), o bien: *al que es (o nace) barrigón (o panzón), aunque lo fajen (de chico) (o aunque lo cinchen) ${ }^{16}$. Entre los apodos están: el Mantecas, el Mantequillas, el Mantecón, la Llanta, el Panza, don Pancho.

La persona -sobre todo la mujer-de c a d e ras a n chas es *nalgona $(\mathrm{S}, \mathrm{M})$, nalgas de oso, fodonga ${ }^{17}$ o fondonga, fodongona (M) o fondongona (M), petacona (S, M; RR, II, 119) ${ }^{18}$, y se le dice para petacas las mias ${ }^{19}$; más groseramente: es de la calidad del tordo, las piernas flacas (o el cuello flaco) y el culo gordo; o bien: es mucho jamón para dos huevos.

De la mujer de bus to grande dicen que es buchona o que tiene su gusto veneciano.

§ 5.-La palabra más general en México para $\mathrm{b}$ a j o de e s t a$\mathrm{t}$ u $\mathrm{r}$ a es *chaparro (S, M); no tiene en sí un matiz afectivo especial ${ }^{20}$. Sí lo tienen, en cambio, las designaciones es un coconete $(\mathrm{S})^{21}$, un centavo o centavito, un * comino o cominito y (más despectivos) un taque$t^{22}$, un sotaco, una *tachuela (S), una corcholata ${ }^{23}$, un tapón, un tapón de alberca ${ }^{24}$ (el bajo y ancho). Algunas veces se dice: es un * piojo, una pulga, un microbio, un gusano. Burlonamente: es *chapaneco $(\mathrm{RD}, \mathrm{I}, \mathrm{S} \text {; cf. } \mathrm{M})^{25}$, es un reintegro, es pariente del suelo, inspector de sótanos ${ }^{26}$, un pedazo de retazo de hombre, es de los Bajos de Ja-

${ }^{14}$ "Tonina Jackson" es el apodo de un luchador ahora muy famoso en México.

${ }^{15}$ Pulquero $=$ 'vendedor de pulque' (S, M).

${ }^{10}$ S y M sólo traen el sentido figurado: "genio y figura hasta la sepultura".

${ }^{17}$ Cf. $\$ \S 19$ y 20.

${ }^{18}$ Petacas $=$ 'asentaderas' (S, M).

${ }^{10}$ Es el lema de una conocida tienda de maletas.

${ }^{20}$ El diminutivo se usa a menudo con intención cariñosa. Chaparrita cuerpo de uva es cumplido para la mujer pequeña y rechoncha; con esas palabras comienza una canción (posterior, evidentemente, al dicho). Chaparro suele aplicarse también a objetos; y para "iqué mala suerte!" el pueblo dice: ¡ah, qué suerte tan chaparra! (¿hasta cuaindo crecerá?) (cf. I y RR, I, 25).

${ }^{21}$ Cf. el $\$ 18$.

${ }^{22}$ Taquete $=$ 'pedazo de madera, que se mete en un hueco, principalmente en los muros (para afianzar clavos)'.

${ }^{23}$ Corcholata = 'tapa de botella (principalmente de refrescos y cerveza) hecha de hoja de lata y forrada por dentro con una ruedecita de corcho'.

${ }^{24}$ Cf. tapón de cuba (Dicc. Acad.).

${ }^{25}$ Chapaneco es variante burlesca de chaparro, formada sobre chiapaneco 'natural del Estado de Chiapas'.

${ }^{26}$ Cf. el $\S 3$. 
lisco ${ }^{27}$. La mujer baja es una chaquira o chaquirita, una lenteja o lentejita, una mentadita ${ }^{28}$. Como apodos se usan el Chapo (RD, M), el Chapa (M), el Enano y Elena, el Medio litro; para mujeres: la Chapis $^{29}$, la Chaquira.

El hombre bajo y fornido, de hombros anchos, es chaparrón $(\mathrm{I})^{30}$ ("Era un hombre de cincuenta años, chaparrón y grueso", IncLÁn, I, 224), está cuadrado ${ }^{31}$ o cuadradote; lo llaman el Cuadrado, el Centimetro cúbico. Cuando un hombre es bajo y fuerte, de buen aspecto, "bien distribuído de carnes", dicen a veces que está ponchadito $^{32}$.

$\S 6 .-$ El individuo d e form e parece un cuasimodo, es un feto, un enano sietemesino. Al e $\mathrm{n} \mathrm{cor} \mathrm{v}$ a d o llaman *jorobado, jorobetas $^{33}$, alcayata, y dicen que está camello o acamellado.

§. 7.-Para decir que una persona está falta d e e n e rg ía fís i c a s, desfallecida, decaída, se dice que está achuchada ${ }^{34}$, que está achahuistlada (RD, S) o que le cayó el chahuistle $(\mathrm{I}, \mathrm{S})^{35}$, que está aguada (RD, S), *lacia, fofa, ponchada ${ }^{36}$, guanga ${ }^{37}$, desguangada, desguanzada (RD, I, S, M?), desguanguilada o desguangüilada (a veces desmangüilada); también: está como el carrizo. Cuando uno se encuentra cansado por un esfuerzo físico está * descuajaringado o descuajeringado ${ }^{39}$. El extenuado por los sufrimientos, trabajos y enfermedades está *acabado, *acabadisimo, *desmejorado, *desmedrado. tado.

${ }^{27}$ Los Altos de Jalisco es el nombre que se da a la parte oriental de ese Es-

${ }^{i s}$ Se entiende "de madre". Mentar la madre a alguien es decirle cierto insulto, el más fuerte de los empleados en el país. Sust. una mentada de madre (véase $\mathrm{S}, \mathrm{s} . \mathrm{v}$. madre y mentada).

${ }^{2}$ A veces también se aplica al hombre: el Chapis; pero por lo común la terminación -is sirve para formar apodos e hipocorísticos femeninos: la Güeris (de la Güera 'Ia Rubia'), la Chiquis (de la Chica), niña popis (de popoff; cf. § 23); Chepis (de Chepa 'Josefina'), Chechis (Cecilia), Lolis (de Lola 'Dolores'), Conchis (de Concha 'Concepción'), Luchis (de Lucha 'Maria Luisa'), Maguis (Margarita), etc.

${ }^{30} \mathrm{~S}$ sólo trae el sentido 'que no llega a verdadero chaparro'.

${ }^{31}$ Cf. el $\S 15$.

${ }^{32}$ Cf., sin embargo, la nota $3^{6}$.

${ }^{38}$ Cf. esp. fam. jorobeta.

${ }^{34}$ Achucharse es, según I, 'arrugarse, encogerse, amilanarse'.

${ }^{35} \mathrm{El}$ chahuistle o chahuiscle es una enfermedad de las gramíneas $(\mathrm{S}, \mathrm{M})$. Las dos expresiones citadas significan también 'abatido moralmente'.

${ }^{36}$ Ponchar es 'picar, punzar, especialmente una llanta [='neumático']; hacerla estallar' (S). Ponchado se aplica también al 'abatido moralmente'.

${ }^{37}$ Cf. el $\S 19$.

${ }^{38}$ Cf. el $\S 19$.

so Ambas palabras se usan también para el objeto 'desvencijado'. 
El niño enfermo o triste está chipil (cf. RD, I, S, M) o, a veces, chipilón ${ }^{40}$.

Aquel a quien le $\mathrm{t}$ i e m b la $\mathrm{n}$ mucho las manos es tembeleque (RD, S) y (como apodos) el Temblores, el Calambres.

\$ 8.-El que tiene las pi e r n a s d e lga das tiene piernas (o patas) de popote ${ }^{41}, \mathrm{o}$ *de alambre, o de chorro de atole ${ }^{42}$ (o de leche); a la mujer de piernas flacas la llaman pajarito.

Cuando alguien $\mathrm{camina}$ i n $\mathrm{garbo}$, con los miembros flojos, camina desguanzado ${ }^{43}$, y le dicen irónicamente dulces meneos (expresión que se aplica a las mujeres que caminan con movimientos ondulantes). Del que c a $\mathrm{m}$ i $\mathrm{n} \mathrm{a} \mathrm{m}$ a l, por tener llagados o adoloridos los pies dicen que anda (o camina) como pollo en tende. dero, como pollo (o gato) espinado (o quemado), como pato asustado (o mareado), como mula espiada, y el que camina con los pi es h a ci a a d e n tro, como perico, como perico en alfombra (o en charola, o en comal $\left.{ }^{44}\right)$, y ha ci a af u e ra, como pato. El que camina con las rodillas ju tas por tener torcidos los pies es *patuleco $(\mathrm{S}, \mathrm{M})$.

Al que c o j e a por un defecto en la pierna o en el pie lo llaman ${ }^{*}$ cojo, *renco, pata chueca ${ }^{45}$, pata chula ${ }^{46}$, pata fria $a^{47}$, pata de ala, pata de ángel; se suele decir además que trae ponchada una llanta ${ }^{48}$. Apodos: el Pala(s) chula(s), la Garza $a^{49}$, el Inmortal ("porque no puede estirar la pata" $\left.{ }^{50}\right)$, el Punto y coma. El que tiene una pierna mutilada está ${ }^{*}$ mocho (M); el que sólo tiene una pierna es o está ${ }^{*}$ cojo, está mocho (S).

El que es $\mathrm{m}$ a $\mathrm{n}$ c o por tener un brazo o una mano inútil es mano chula o mano fria; el que lo es por tener el brazo torcido es mano de manivela o tiene desequilibrada (o chueca) una (o la) tenaza; el que

\footnotetext{
${ }^{40}$ En sentido estricto, se dice que un niño se pone chipil cuando su madre espera otro niño y él (a causa de eso) se pone irritable, quiere que lo mimen, etc. Por extensión se aplica al hombre que se siente enfermo (con náuseas, etc.) cuando su mujer va a tener un niño.

${ }^{41}$ Popote = 'paja para tomar refrescos' $(\mathrm{S}, \mathrm{M})$.

${ }^{42}$ Atole = 'bebida que se prepara con harina, comúnmente de maíz, disuelta con agua o lcche' (Dicc. Acad.).

43 Para desguanzado, cf. el $\$ 7$.

${ }^{44}$ Comal $=$ 'disco de barro o lámina sobre el cual se cuecen las tortillas' (S, M).

${ }_{45}$ Chueco = 'torcido'.

${ }^{40}$ Cf. chulenco 'patojo' (Venezuela), 'renco, cellenco' (Colombia) (M. L.

WAGNER, "El sufijo hispanoamericano -eco", NRFH, IV, 1950, pág. 113).

${ }^{47} \mathrm{Cf}$. en seguida mano fria, y en el $\S 19$ diente frio.

${ }^{48}$ Cf. la nota 36 .

${ }^{49}$ Según S, garza es en México 'persona de pescuezo muy largo'.

${ }^{50}$ Estirar la pata, vulgar por 'morir' (S, s. v. pata).
} 
lo es por faltarle una parte del brazo o una mano está *mocho (M); cuando le falta todo el brazo es o está *manco, está mocho (S).

$\S 9$--La c a b e z a pequeña es cabeza de alfiler, o de alpiste, o de garbanzo. Al que se rapa la cabeza le dicen nido de avispas. Cara de palanqueta ${ }^{51}$ es la c a r a redonda; cara de frontón o de choque, la aplanada; cara torteada, la redonda y aplanada. El que tiene las m e jilla s abultadas es *cachetón (S, M), o* mofletudo.

Al c a c a r a ñ a d o le dicen cacarizo (RD, I, S, M), * cacarañado, * picado (S), róido (entre gente inculta). Burlescamente: está cucaracho (S, M) o cúcara, tiene cara de (o parece) coladera, o más grosero, tiene cara de mierda (o caca) llovida. También se le dice irónicamente cutis de colegiala, que es lo que promete la propaganda del jabón "Palmolive"; por la misma razón se usa el apodo el Palmolive, además de el Cácaro, el Cúcara.

$\mathrm{El}$ pecos o es (o parece) huevo de pipilas2 ("Y esa cara pecosa y empañada como huevo de pípila", INCLÁn, I, 267), y también se dice que tiene cara de mierda (o caca) llovida.

$\S$ 10.-Al peli r rojo se le aplican las designaciones cabeza de cerillo $^{53}$, semáforo, fluorescente, muchacho (-a) en tecnicolor, y. el apodo el Colorado. El r u b i o es cabeza de jilote $e^{54}$; la mujer que se tiñe el pelo de color rubio es (güerañ) oxigenada o también güera a fuerzas.

El que lleva el c a b ello d e sorde $\mathrm{n}$ a d o es o está * greñudo, *desgreñado (S), mechudo (RA, II, 34; S) ${ }^{56}$, desmechado (I, S), copetón ${ }^{57}$. En son de mofa dicen que tiene cabeza de escoba (o de plumero), o cabeza de medusa o mechas de alcalde viejo, que parece pájara brava o que parece la madre del aire, que está chino ${ }^{58}$ de no peinarse (y enmarañado de tanto rascarse), que no más se peinó y se vino, que es terror de la peluqueria, que ya lo lazan (se entiende "al pasar por una peluquería”); también exclaman iqué me-le-notas!"s9 Se usan como apodos el Greñas, el Melenitas, el Copetes, el Mechas,

"5a palanqueta es un dulce redondo y plano, que se hace de caramelo y cacahuate o pepitas (según S, de maíz tostado y molido, amasado con miel).

${ }^{\text {s2 }}$ Pipila = 'pava' (S).

${ }^{53}$ Cerillo es en México palabra más usual que fósforo (cerilla no se usa nunca).

${ }^{54}$ Jilote $=$ 'mazorca muy tierna de maíz' (S); sus cabellitos son de color dorado.

${ }^{55}$ Güero es la palabra más usada en México para 'rubio'.

${ }^{56}$ Mechas = 'greñas'.

57 C.f. el $\$ 23$.

${ }_{58}$ Pelo chino $=$ 'pelo crespo'.

58 Cf. iqué me-notas!, § 14 . 
el Plumero, el Beethoven, el Glostora(s) (irónico: es nombre de una brillantina), el Aracuán ${ }^{60}$.

$\S$ 11.-La persona de ojos oblicuos es chale chi $^{\text {, y }}$ sus ojos son achalados o estirados; con burla: ojos de rajadura de alcancía.

Al de ojos chicos le dicen humorísticamente que los tiene de rendija, o de pingüica ${ }^{62}$, o de pulga (pedorra, vulg.), o de apipizca dormilona ${ }^{63}$.

Tener los ojos grandes y saltones es tenerlos de rana, * de sapo, de pescado, de toro loco, o bien ser un ojotón. Apodos: la Rana, el Sapo, el Pescado, el Ojitos, el Ojotón.

Los o jos láng ú id os son ojos de borrego (o de chivo) ahorcado (o a medio morir). El que tiene los párpados caídos es pistiojo ${ }^{64}$.

El mi o p e es *cegatón (RD, I, S) o pariente de los topos.

Para bizco, además de ${ }^{*}$ bizco, se dice bizcocho, *vizconde, Vizconde de Mirachueco, bizcornete ${ }^{*}$ bizcorneto $(\mathrm{S}, \mathrm{M})^{65}$, *virolo $(\mathrm{S})^{66}$, vitrinas ("está medio vitrinas"); también se dice que tiene ojos encontrados, que hace chiras ${ }^{67}$, que se le van los ojos (o un ojo cuando parece bizco por tener un ojo inmóvil), y, humorísticamente, que no tiene problema para ver un partido de tenis. Apodo de bizco y de tuerto es el Poca luz; a los dos suelen decir, casi como ofensa, ime mirabas!

El hombre d e a n t e ojos es lentejudo, lentejas, antiparro; es *cuatro ojos y también cuatro lámparas y cuatro milpas ${ }^{68}$, que a veces se convierte en cuatro mil para hoy (grito de vendedor de billetes de lotería). Además le dicen semáforo y ciego.

Para el que tiene muchas $\mathrm{l}$ e g a $\tilde{\mathrm{n}}$ a s se usan chinguiñoso (RD, $\mathrm{I}, \mathrm{S}, \mathrm{M})^{69},{ }^{*}$ legañoso y *lagañoso; * pitañoso es menos frecuente.

$\S$ 12.-Equivalentes de sordo son soreco $(\mathrm{M})$, soreque $(\mathrm{M})^{70}$,

${ }^{60}$ Aracuán $=$ aracuão, pajarito brasileño de copete desordenado, popularizado por Walt Disney.

"Chale es el apodo que se da en México al chino (S, M).

${ }^{62}$ Para pinguiica, cf. $\S 18$ y nota 109 .

${ }^{63}$ Apipizca o apipixca = 'ave acuática migratoria de México' (S).

${ }^{6 t}$ RD trae pixtiojo 'legañoso, pitarroso'.

${ }^{65}$ Sobre bizcorneto, bizcoreto (Honduras, Nicaragua), cf. M. L. WaGNer, art. cit., pág. 107 .

${ }^{66} \mathrm{~S}$ sólo lo da para Colombia.

${ }^{67}$ En el juego de canicas, chiras es la jugada con que se pega a varias canicas a la vez.

${ }^{68}$ La milpa es la 'tierra destinada al cultivo del maíz y de otras semillas' (Dicc. Acad.) y además la 'mata de maíz'. "Cuatro milpas tan sólo han quedado" es comienzo de una canción.

${ }^{69}$ Chinguiña = 'legaña' $(S)$.

io S sólo trae soreco y con el sentido de 'zonzo, tonto, principalmente por sordera'. Cf. M. L. WAGNER, art. cit., pág. 110. 
sordeleque; además es un palo, una tapia, y está *sordo como una tapia. El que tiene ore jas $\mathrm{grand}$ es las tiene de papelote ${ }^{71}$ o de soplador, y lo llaman Dumbo (por el elefantito de grandes orejas en los dibujos de Walt Disney).

El de $\mathrm{n}$ a riz grande es *narigón, *narizón (RD, S) y tiene narices de alcanzaqueso; le suelen poner de apodo el Narices, el $\mathrm{Na}$ rizotas (S). El de narices a g u i l e ̃̃ a s las tiene de alcayata o de hueso de mango. La nariz $1 \mathrm{l}$ a $\mathrm{n}$ a es ${ }^{*}$ chata, lo mismo que la persona que así la tiene. La nariz $\mathrm{r}$ e s p in $\mathrm{g}$ a $\mathrm{d}$ a es, vulgarmente de huelepedos o de huelecaca; la mujer que la tiene es chata narigata.

$\S$ 13.-El que tiene la b o c a g r a n d e es *bocón, *jetón (S), *hocicón, *trompudo (S, M); tiene boca de buzón, o de alcancia, o de chancla, o de garage (pron. garáš), o de zaguán abierto. Con labios gruesos: boca de holán, trompa de hule. Humorísticamente se dice que tiene la boca tan grande que se aconseja ${ }^{72}$ (o se cuchichea) solo. Son apodos el Trompas, el Trompitas, el Boquitas.

La boca chica es de silbido, de chiflido, de quiupi (del inglés kewpie 'muñeco que representa un Cupido').

El individuo de la bio le porino es tencua $(\mathrm{S}, \mathrm{M})^{\mathrm{i3}}$, cucho (S, M) o queque.

Términos descriptivos para 'd e s d e $\mathrm{n}$ t a d o' son chimuelo (RD, $\mathrm{S}, \mathrm{M})$ (el más frecuente), ${ }^{*}$ desmolado, molenque. Para el que tiene los dientes I a rgos y salidos, *dientón (S), diente frio, dientes de mula maicera.

Del bi g ot e grande y caído se dice bigotes de aguacero o bigotes pulqueros ${ }^{74}$. El que tenía bigote y se lo quitó parece cura, parece culo de gallina o tiene boca de nalgas de niño chiquito.

La persona que tiene algún d ef e c to d e pron un c i a ción (cualquiera que sea) habla mocho, habla *trabado, es *tartajosa o tiene lengua de hilacha (cf. en España lengua de trapo). La que ganguea habla *gangoso o tiene frenillo (también se dice de la que pronuncia la $r$ rehilante). ${ }^{*}$ Tartamudo tiene la acepción general.

\section{2) Belleza}

§ 14.-De la m u j e r g u a p a los hombres dicen que está como mango, que es un mango o un mangazo, o un real mango, o un mango (S, M).

${ }^{71}$ Papelote es deformación, por etimología popular, de papalote 'cometa'

i2 Cuando dos personas cuchichean entre sí se dice que "se aconsejan".

${ }^{73} \mathrm{RD}$ trae tencuas.

${ }^{74}$ Porque al beber el pulque se empapan. 
de Manila ${ }^{7 \overline{5}}$; que es un rifle o está como rifle, que es un injerto de rifle y mango; que es una perita en dulce; además: es una mujer *de no malos bigotes, no está tan peor.

La mujer atractiva y jo ve $\mathrm{n}$ es una cosita, es una changuita ${ }^{76}$, está que se cae (del árbol, o de buena), está pa' tronarle los huesitos. De la a $1 \mathrm{ta}$ y for $\mathrm{n}$ id a dicen que está muy bien dada.

Más vulgares y más limitadas a conversaciones entre hombres son las siguientes expresiones: está buena, buenota, buenisima, rebuena; está sazona $a^{77}$; es un (o está) cuero $(\mathrm{S}, \mathrm{M})^{78}$ ("Un cuero a todo meter" ${ }^{2}$, Salazar Mallén, 11; “¿Qué tiene? Cuero no está, ni joven”, ibid., 74), es un cuerito, o un cuerazo; es un forro ${ }^{80}$ ("Ni que Justina fuera tan buen forro para que anden a carambazos por ella", ibid., 215), o un forrazo, o un forrito; es un pato o un patazo; es un fierro; es una chamacona $^{81}$, un mujerón (cf. S), un viejón, un viejorrón ${ }^{82}$. Muy vulgar: es un (buen) culo o un fundillo. Para la mujer a $\mathrm{lt}$ a y $\mathrm{ro-}$ b u sta: es un burro, un caballote ${ }^{83}$, un monumento (muy usado); para la de caderas a $\mathrm{nch}$ a s dicen iqué me-notas! ${ }^{84}$. La atractiva y volu ptu os a es muy cachonda, birrionda o caliente ${ }^{85}$.

$\S$ 15.-Las mujeres se refieren al ho m b r e g u a po diciendo

is El mango "de Manila" es el más reputado en México: es carnoso, dulce, de hueso delgado.

${ }^{76}$ Mi changuita $(-\circ)=$ 'mi novia (-o)'. También changa, chango significan 'novia, novio', y además 'mujer, hombre': “Dos changas muy padres ['guapas'] andaban sueltas", García Arroyo, 70.

it Cf. Alfredo M. SaAvedra, "El caló de la delincuencia y la expresión sexual”, $A S F M$, II, 1941, pág. 36.

is También 'mujer, amante' (RD, S) : "era mi cuero", Salazar Mallén, 2i1. Hay una graciosa frase (citada por RD): icuántos cueritos, y yo sin zapatos!

${ }^{7 \theta}$ A todo meter (como a todo dar, a toda madre, a toda máquina, a todo tren, a todo trapo, a todo mecate) es expresión general de encarecimiento = 'estupendo, magnífico'.

so Equivale también a 'mujer, concubina' (cf. RD).-En la cita que sigue, carambazo = 'trancazo, golpe'.

${ }^{81}$ Chamaco, $-a=$ 'muchacho, $-\mathrm{a}$ '.

${ }^{82}$ Vieja es despectivo general para 'mujer': "No creas que esa vieja me va a enseñar", Salazar Mallén, 51. En la pubertad, los niños llaman a las mujeres (también a las niñas) las viejas. Usado entre. hombres (principalmente de la clase baja) puede cobrar sentido positivo; así, de una mujer guapa: "iqué vieja!"; de ahí viejón y viejorrón. Cf. nota 89 .

${ }^{83}$ Despectivamente se dice de la mujer demasiado corpulenta que es un caballón o una caballona.

${ }^{84}$ Se entiende: "iqué buenotas caderas!" (o más bien petacas). La sustitución de $b$ por $m$ es propia del lenguaje empleado con los niños chicos ("méngashe con su abuelita" por "véngase...").-Cf. iqué me-le-notas!, § 10.

${ }^{\mathrm{s} \sigma}$ Estar o ponerse cachondo, birriondo o caliente es 'sentirse excitado sexualmente'. Cf. el $\S 16$. 
que está como (o es un) mango o rifle; los hombres dicen de él que es un (o muy) tipo, un tipazo.

El hombre vi g o r o s o está muy bien dado, es o está * fortachón, está fibrudo o es un(a) fibra, está doblado ${ }^{86}$ o dobladote, es de doble ancho, está cuadrado o cuadradote ${ }^{87}$, está *trabado, correoso, *duro. Además: es un ${ }^{*}$ toro, un torote o un torazo; es un peladote ${ }^{88}$; es canilludo o tiene canilla (I, M) ("Presume mucho de tener canilla para contrarrestarme”, INCLÁN, I, 251).

\section{3) EdAd}

$\S$ 16.-Para decir, sin intención especial, que un hombre es $\mathrm{d} e$ a va $\mathrm{nzada}$ e dad, se dice que es o está ${ }^{*}$ viejo ${ }^{89}$ o grande (I, S). Con simpatía se dice que está (o es un) ruco ${ }^{90}$ o ruquito, rucano o. rucanito $(\mathrm{M})$, viejano ${ }^{91}$, vejarano ( $\left.\mathrm{RD}, \mathrm{S}, \mathrm{M}\right)$; cuando está lleno de arrugas es una pasita.

Despectivamente, el anciano ca d u co es un *arcamal o, con más frecuencia, un *arcamán ( $\mathrm{M}$ ), está cáncano ( $\mathrm{S}$ ) o cáncamo ("Si no fuera porque ya estará muy cáncama y con una chorrera [ $=$ 'un montón'] de hijos...", InClán, II, 326), está *chocho y *chochea, está pachiche (RD) o pachichi ${ }^{92}$, está teleque ${ }^{93}$, tembeleque $(\mathrm{S})_{*^{94}}$, *veterano (S), *vejancón, viernes $(\mathrm{M})$; está vetarro o es un vetarro (RD), un viejo cáscara. Humorísticamente se dice que ya está anterior, que ya está macicito, que ya no se cuece (o coce) de un (o al primer) hervor (RR, II, 15), que se pega en las vigas (como las telarañas viejas).

El vi ejo e namoradizo, además de *viejo (rabo) verde, es (viejo) chirrisco (I, S, M) ("No lo dejes que te enamore. Es muy chirrisco..., y le gustan mucho las muchachas bonitas", Delgado,

${ }^{86}$ Según el Dicc. Acad., en España se llama doblado al hombre 'de pequeña o mediana estatura y recio y fuerte de miembros'.

${ }^{x} \mathrm{r}$ C. el $\$ 5$.

${ }^{8}$ Pelado es en general el término que aplican la clase media y la alta al hombre de la clase baja, pobre e inculto. Por extensión es el individuo de mala educación y el que emplea palabras groseras ("peladas") (S, M). Pero tam. bién se usa con el sentido de 'individuo, fulano' ("ese pelado tuvo la ocurrencia de..."); de aquí seguramente peladote = 'hombre fuerte'.

${ }^{89}$ Viejo, vieja es tratamiento cariñoso de mujer a marido y viceversa. Sobre vieja, cf. además la nota 82 .

${ }^{90}$ Mi ruca $=$ 'mi novia'. En Arizona ruco, ruca es tratamiento cariñoso entre marido y mujer.

${ }^{91} \mathrm{~S}$ trae viejanco.

${ }^{* 2}$ Las dos formas se aplican también al 'fruto pasado' (M). S sólo da el sentido de 'seco, pequeño'.

${ }^{93}$ Según $\mathrm{S}$ y $\mathrm{M}$, en Chile se usa telenque, con el sentido de 'enclenque, trémulo, tembloroso; expuesto a caer, vacilante'.

${ }^{94}$ Cf. el $\$ 7$. 
pág. 97), (viejo) lagartón, viejo cachondo, o birriondo, o caliente ${ }^{95}$; vulgarmente dicen que ya ni rascándole el lomo (del impotente).

A la mujer de cierta edad y c él i b e la llaman cotorra y *cotorrona $(\mathrm{I}), \mathrm{o}$ *solterona, quedada $(\mathrm{S})$, señorita quedada, y dicen que ${ }^{*}$ se quedó para vestir santos (S). Para el hombre célibe sólo conocemos *solterón $\mathrm{y} *$ cotorrón.

$\$$ 17.-De las cos a s a n i c u a d a s dicen familiarmente que son del año del caldo $(\mathbf{S})^{96}$, del año de la calabaza, o de la caperuza, o de la hebra, o de la nañica ${ }^{97}$, o de la canica, o ${ }^{*}$ del rey que rabió, o ${ }^{*}$ de Maria Castaña; de cuando las viboras andaban paradas ${ }^{98}$ o de cuando amarraban perros con longaniza (y no se la comian); de allá de cuando marras; de tiempos de don Porfirio; de la pelea pasada (también se aplica a la persona de ideas anticuadas). Además: más viejo que el atole ${ }^{99}$, o que la roña, o que ${ }^{*}$ Matusalén. La cosa vieja de tan repetida está ${ }^{*}$ trillada y, sobre todo, está choteada (RD).

$\S$ 18.-En la pubertad, los muchachos (y a veces las muchachas) están en la ${ }^{*}$ edad de la punzada (S, M), o bien en la edad de la choca $a^{100}$, o de la bicicleta, o del plomo, o del pato ${ }^{101}$. Del adolescente se dice además que todavia huele a orines (o a libros), que todavia no escupe en rueda.

A los $\mathrm{n}$ i ñ os, cuando son muy chiquitos, los llaman pirinolas ${ }^{102}$, pingüicas ${ }^{103}$, pirruñas, ${ }^{*}$ coconetes $(\mathrm{I}, \mathrm{S}, \mathrm{M})^{104},{ }^{*}$ chiquillos, chiquirringos, chipilingos $(\mathrm{S}, \mathbf{M})^{105}$, chiquirristingos, chipirristingos, mo$\cos$ ("semejante moco y ya fuma"). El niño que quiere parecer grande es ${ }^{*}$ agrandado (M); la niña parece señorita recortada ${ }^{106}$.

Cuando se habla con enojo o desprecio a un niño, se le dice *mocoso, * mocosito, escuincle o escuintle (RD, S, M).

El be n jamin de la familia es, entre el pueblo, xocoyote $(\mathrm{RD})^{107}$; le dicen sope de(l) perro, porque el resto de la masa con que

${ }^{85}$ C.f. el $\$ 14$.

* Esta expresión (que es la más usual) y las siguientes se suelen usar también con del tiempo de..., de la época de...; lo más frecuente parece ser, sin embargo, del año de...

${ }^{97}$ Cf. el año de la nanita (Dicc. Acad.).

"Cf. la nota 9 .

"Para atole, cf. nota 42.

${ }^{100}$ Quizá de chocante 'antipático' (S, M).

${ }^{101}$ Cf. en España edad del pavo.

${ }^{102}=$ perinola .

${ }^{103}$ Pinguiica, por el fruto (muy pequeño) de la planta de ese nombre (cf. S) .

${ }^{104}$ C.f. el $\S 5$.

${ }_{105}$ RD trae chipilingue. Cuba).

${ }^{100}$ Recortado se aplica, según S, a la 'persona de baja estatura' (México y

${ }^{102}$ Fem. la xocoyota. Pron. šocoyote. Moctezuma Xocoyotzin es 'el menor'. 
se han hecho tortillas suele aprovecharse para hacer sopes ('tortillas pequeñas y gruesas') para los perros.

\section{VESTIDO Y PRESENTAGIÓN}

\section{1) Desaliño}

$\S 19$ - - La persona -sobre todo la mujer- descuidada y que $\mathrm{v}$ is t e con d e s a li ñ o es muy chancla ${ }^{108}$, muy cuachalota ${ }^{109}$, muy fodonga $(\mathrm{I}, \mathrm{S})^{110}$, muy ${ }^{*}$ dejada; cuando se la ve desaliñada se dice que está o anda descuacharrangada (RD, M) ${ }^{111}$, * desgarranchada (S, cf. M), desgualichada, desguanguilada (S) o desguangüilada ${ }^{112},{ }^{*}$ fachosa ${ }^{113}$, *fachuda (S, cf. I), *en fachas, guandaja (M), guandajona $(\mathrm{S}, \mathrm{M}),{ }^{*}$ pingajosa, *zaparrastrosa, *chaparrastrosa $(\mathrm{S}, \mathrm{M}) \mathrm{o}^{*}$ zarrapas. trosa, xonga (RD) $)^{114}$, mal fajada. Se suele decir: no es que sea tan fea, lo que pasa es que está mal cuidada, o no es que sea tan gorda (Chepa), lo que tiene es mal fajada (RR, II, 22)115; además: anda toda por ningún lado.

La mujer d e sorde $\mathrm{n}$ a d a en el manejo de su casa es destorlongada $(\mathrm{I})^{116}$.

El harapiento es *andrajoso, *hilachento (S, M) o hilachiento, está hecho (o parece) un *judas (tronado) (RA, II, 115 ; S), anda ${ }^{*}$ como estropajo o como trapo de sacudir.

Cuando uno lleva el traje demasiado grande o chico, dicen en son de burla: era más grande (o más chico) el difunto, o el difunto era demasiado grande (o chico). El individuo flaco y alto que trae el traje flojo parece *espantapájaros. Rabón (S) y *zancón (S, $M)^{117}$ designan a la persona que lleva el vestido demasiado corto ("iQué rabona!", Azuela, La luciérnaga, 172; "le gusta andar muy zancona"), y también suelen aplicarse al vestido mismo ("Unos calzoncitos de crea, su bata rabona, su sombrero de paja", INCLÁn, II, 396). El pantalón demasiado corto es pantalón de brincacharcos, y del que lo lleva dicen que parece que está espiando. La prenda de

${ }^{108}$ Chancla significa también 'torpe, que hace mal las cosas' (cf. RD).

${ }^{109}$ Véase el $\S 20$.

110 Véanse $\$ \$ 4,20$.

${ }^{111}$ Se aplica también a cosas destartaladas. RD dice que equivale además a 'despilfarrado' y 'distraído'.

${ }^{12}$ Cf. supra, $\$ 7$.

${ }^{113}$ Cf. $\$ \S 21,22$.

${ }_{114}$ Pron. šonga; es palabra indígena, no muy generalizada en la Capital.

115 También puede aplicarse a la persona mal educada.

${ }^{11 B}$ Según $\mathrm{S}$ y M, 'destornillado, manirroto, botarate'.

${ }^{117}$ Cf. el $\$ 3$. 
vestir demasiado holgada y amplia es o queda ${ }^{*}$ guanga $(\mathrm{S}, \mathbf{M})^{118}$ o guangacha ${ }^{119}$.

$\S$ 20.-Los adjetivos más frecuentes para denotar s u cie d a d son: *cochino, *puerco, *sucio, *mugroso (S); a veces: ${ }^{*}$ mugriento $o^{*}$ mugre; además se usan: cuachalote, ${ }^{*}$ cochambroso ${ }^{120}$, chamagoso (RD, I, S, M) ("Pequeños chamagosos, descalzos, iban y venían", Azuela, Nueva burguesia, 88), charrasqueado o charrasquiado ${ }^{121}$, * chorreado (RD, I, S, M), * chorriado o churriado, que se aplican sobre todo al niño que tiene la cara sucia ("AAy! qué chorreadita estás, chula", IncLán, I, 433), *asqueroso ${ }^{122}$, fodongo (RD, I, S, M $)^{123}$ ("¿Ud. cree, don Pepe, que sean tan fodongos, que hacía quince días que no se mudaban la camisa?", INcLÁN, I, 346), fodongón, mantecoso, atascado ${ }^{124}$. Del sucio dicen también que anda todo *emporcado (o empuercado), que parece pepenador ${ }^{125}$, o chicharronero, o carbonero, o adobero, o cargador de la Merced ${ }^{126}$; que se cae de mugroso. El que lleva la cara sucia tiene cara de chivo miado.

\section{2) Elegancia y SU EXAGERACión}

\$21.-Con admiración se dice del hombre e lega n t e y apuesto que es o está *bien plantado o *bien trajeado; cuando se le ve caminar con garbo se dice que anda muy * giro (I, cf. M) o-ya con cierto matiz de burla- muy girillo ${ }^{127}$.

${ }^{118}$ Me viene guango decimos con desdén y autosuficiencia de la cosa que juzgamos demasiado fácil para nosotros o de la persona que creemos inferior en fuerzas, etc. Se dice respondiendo a un desafío ("-Fulano dijo que si te encontraba te las verias negras... - ¿Ése? Me viene guango").

119 RD trae guanguacho, I guangochudo.

${ }^{120} S$ trae cochambreado. En Arizona se dice cochambrudo o cuachambrudo.

121 Significa también y principalmente 'herido con arma blanca; que tiene cicatriz, sobre todo en la cara' (cf. S).

${ }^{122}$ Como en otros países, asqueroso se usa también en el sentido inverso de 'propenso al asco, que tiene la manía de la limpieza; difícil cle contentar': "Nada tenía yo de asqueroso ni tampoco un gusto especial, sino que todas generalmente me gustaban", Inclán, II, 1o. Del hipócrita suele decirse que es de los asquerosos que comen mierda. Con el mismo sentido, asquiento (S).

${ }^{123}$ Cf. $\$ \$ 4$ y 19 .

${ }^{12.4}$ Atascado es también 'tonto' (S), 'bruto', 'que obra precipitadamente'; además se usa como insulto general. En el Sureste de México (S), en Sonora y en Arizona equivale a 'lodoso'.

${ }^{125}$ Pepenador es el 'hombre que busca y recoge de entre los escombros y la basura papeles y objetos que puede vender' (cf. S).

12t "La Merced" es uno de los grandes mercados de la Capital. Carga. $d o r=$ 'mozo de cordel'.

12: Giro se llama al 'gallo de plumaje matizado de amarillo, o de blanco y negro' (S). Su plumaje se tiene por vistoso, y de ahí y del modo de andar de 
Las designaciones siguientes, aunque son positivas, se dicen casi siempre con cierta ironía benévola; todas expresan la idea de 'elegancia': está (o anda) muy elegantiosa ${ }^{128}$, muy *cuca, muy *curra, muy ${ }^{*}$ catrina (RD, I, S) o encatrinada (M), muy ${ }^{*}$ fachosa (M) ${ }^{129}$ ("¿Ve usted ese ir y venir en coche, ese lucir anillos, ese pasear blusas estrenadas y medir a los pobres con los ojos? ... ¡F Fachosas!", ÁNGEL DE CAMpo, 182), muy *peripuesta, muy prendida (M), muy plantada, muy * planchada $(\mathrm{S}, \mathbf{M})^{\mathbf{1 3 0}}$, muy trajeada. Los tres últimos se aplican sobre todo al hombre; también se dice de él que anda muy padrote ${ }^{131}$. Además: se cae (o azota ${ }^{132}$ ) de elegante. El que se viste con elegancia y antes no lo hacía está echado a perder; se le pregunta en son de mofa: :dónde hubo palo ensebado? ${ }^{133}$, o bien ¿lladrónde (te compraste ese traje, te hiciste ese vestido, etc.)?134

$\S$ 22.-Las expresiones siguientes se aplican a la persona $\mathrm{m} \mathrm{u} \mathrm{y}$ a r r e g la da y com pu es t a: está o anda muy*emperejilada, muy *emperifollada, muy entacuchada ${ }^{135}$, muy pomadosa (RA, II, 104; $\mathrm{S}$, cf. M), va de mucha pomada (RA, ibid.; M), está o anda muy *almidonada, muy *encolada (I; cf. S, M), muy *relamida o *lamida ${ }^{136}$. A veces se dice: va de cola parada y almartigón (RA, II, 104), o de levitón y cola parada, o de pipa y anteojos, o de pipa, 'anteojos y cola amarrada, o de pipa, guante y bastón.

Francamente despectivas son las palabras que designan a la persona (principalmente a la mujer) que resulta ridícula por ir recargada de adornos: *cursi, *fachosa (M), escandalosa

los gallos viene, sin duda, la expresión.-Cuando un hombre se arregla con esmero para impresionar a una mujer se dice que anda girillo tras fulana.

${ }^{128} \mathrm{~S}$ trae elegantoso.

${ }^{129}$ RD, I, S, M, y el Dicc. Acad. dan sólo el sentido de 'fachendoso'.-Cf. $\S \S 19,22$.

${ }^{130}$ Planchado significa además 'listo; valiente' (S). S limita a Centroamérica la acepción 'elegante'.

${ }^{131}$ Cf. el $\S 24$.

${ }^{132}$ Azotar = 'caerse' Es palabra menos noble pero más vigorosa que caerse; da idea del golpe recibido. ;Azotó la res! se dice cuando alguien cae al suelo. También = 'pagar' ("tuve que azotar con cincuenta pesos").

${ }^{133} \mathrm{El}$ palo ensebado (S, M) es la cucaña española; el premio consiste muchas veces en prendas de vestir.

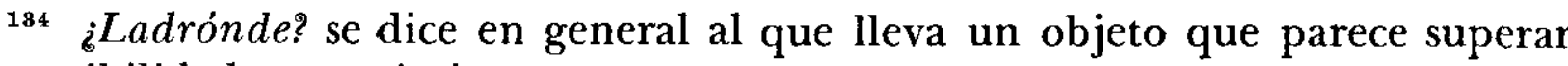
sus posibilidades económicas.

135 Tacuche es en algunas partes de México 'envoltorio de trapos, lio', y por extensión, 'traje, vestido' (S). Entacucharse = 'vestirse con exageración', o sim. plemente 'vestirse'.

136 Ambas palabras se aplican también al hombre que se peina con mucha grasa y lleva el cabello untado a la cabeza. 
(cf. S), * charra $(\mathrm{S})^{137}$, fifi ${ }^{138}$, visionuda $(\mathrm{S}, \mathrm{s} . \mathrm{v} \text {. visionero; } \mathrm{M})^{139},{ }^{*}$ figurosa (M) ("Después les puso muchos defectos a nuestros trajes, asegurando que nunca nos había visto tan figurosos", Azuela, Las tribulaciones, 68); a veces dicen que no más le faltó ponerse (o que se cuelga hasta) la mano del metate ${ }^{140}$.

La mujer excesivamente $\mathrm{m}$ a q $\mathrm{u}$ illada parece máscara, parece tlapaleria ${ }^{141}$; también: se le pasó la mano de tlapaleria o se le pasó la mano de gato.

§ 23.-Las siguientes designaciones se aplican sobre todo a la persona de alta posición social, orgullosa y vanidosa, pero también suelen usarse para la que alardea de su elegancia: *estirado, apretado, *empaquetado (RD), paquetudo (M), *encopetado (cf. S), copetón (I, M) y -palabra de reciente introducción y muy en bogapopoffit2.

Al joven o muchacha elegante, de la alta sociedad, llaman principalmente *niño (-a) bien, y a veces *niño $(-a)$ pera o ${ }^{*}$ litri.

$\S 24 .-\mathrm{El}$ p i s a v e r d e se llama en México fifi (S) ("El llamado Tito era un fifí almidonado y antipático", Azuela, Nueva burguesia, 28), fifirucho y *fifiriche (RD, M; cf. I) (ambas palabras designan al fifí flaco y enclenque), roto (I, S. v. catrin $\left.{ }^{143} ; \mathrm{RD}, \mathrm{S}, \mathrm{M}\right)$, rotäto, palabra que junto con su forma femenina, rota, rotita, se aplica a la persona que, teniendo poco dinero, se afana por vestir elegantemente; la usa mucho el pueblo para designar con desprecio al señorito o a la señorita de la clase media que viste con lujo ("Muchos andan como nosotros; todo se vuelve apariencia, y en lo interior pasan sus miserias bien crueles. A esto llaman «rotos»”, FERnÁndEZ DE Lizardi, Periquillo sarniento, I, xvir; citado por I; "Odiaba a las elegantes, a las rotas que visten de seda”, ÁNGEL DE CAMPo, 38). También se usa rotinfacio.

${ }^{137}$ Charro se dice también de la prenda de vestir de colores chillones y de mal gusto (cf. Dicc. Acad.).

${ }^{138}$ Cf. el $\S 24$.

139 Visionuda es también la persona de conducta extravagante.

${ }^{140}$ Mano de metate $=$ 'cilindro de piedra con que se muele en el metate' (S, s. v. mano). M trae ponerse hasta la mano del almirez (México).

${ }^{1+1}$ Tlapaleria $=$ 'tienda en que se venden pinturas, quincalla, objetos para el hogar, etc.' (S, M).

${ }^{142}$ Esta palabra, que hace unos años se limitaba a un círculo reducido, fué divulgada por los periódicos; uno de ellos publica todos los domingos una sección intitulada "Ensalada popoff", que comenta los acontecimientos de la alta sociedad.

${ }^{143}$ La palabra catrin 'pisaverde', muy común en el siglo pasado, no se emplea actualmente (ya Icazbalceta dice en 1899: "esta palabra se va anticuando"). Hoy sólo se usa como adjetivo (='elegante'; cf. $§ 21$ ). 
Aquí hay que mencionar a los tarzanes, pachucos y padrotes. Tarzán se llamaba hace unos años a un tipo de malvivientes de presentación e indumentaria muy especiales: pelo largo sobre la nuca, pantalones anchos, fajados por encima de la cintura, cadena de reloj, etc. Fué sustituído después por el pachuco, que surgió hacia $193^{\circ}$ en el Sur de los Estados Unidos ${ }^{144}$ y llegó más tarde a México, donde ahora comienza a pasar de moda. El pachuco viste amplia y larga chaqueta a cuadros; pantalón de color muy distinto, ancho arriba y estrecho abajo, sostenido con tirantes a medio pecho; corbata de lazo de color chillante, comúnmente con dibujo de puntitos; sombrero de ala ancha y plana, con una pluma llamativa; zapatos holgados y toscos, casi siempre blancos; lleva el cabello largo, rematado atrás en una "cola de pato", con un copete sobre la frente y abundantemente untado con brillantina perfumada; se adorna con una larguísima cadena de reloj, que cuelga visiblemente desde el cinturón hasta el bolsillo del pantalón, pasando por la rodilla; trae también una navaja de bolsillo, con la cual suele limpiarse las uñas en público. Los pachucos son vagos, vividores, mujeriegos, gigolós, valentones; provienen por lo común de la clase baja.

Padrote $^{145}$ es en sentido estricto el 'alcahuete que provee de parroquianos la casa de tolerancia; jefe de mancebía' (S, M), y el 'hombre que vive de una mujer' (S). Pero el término se aplica además al individuo mujeriego y vividor de cualquier clase social, bien parecido y vestido con esmero y aun afectación. No es un tipo especializado como los dos anteriores; su indumentaria varía con la clase social a que pertenece; algunas veces adopta la del pachuco.

Por último, el pisaverde de modestas condiciones se llama quintopatiero, fifi de barrio ("Diciendo ... que el motorista era un fifí de barrio", Azuela, Nueva burguesia, 24) y pachuco (o padrotito) de banqueta ${ }^{146}$.

El Colegio de México.

Margit Frenk Alatorre

\section{INDICE DE VOCES Y GIROS}

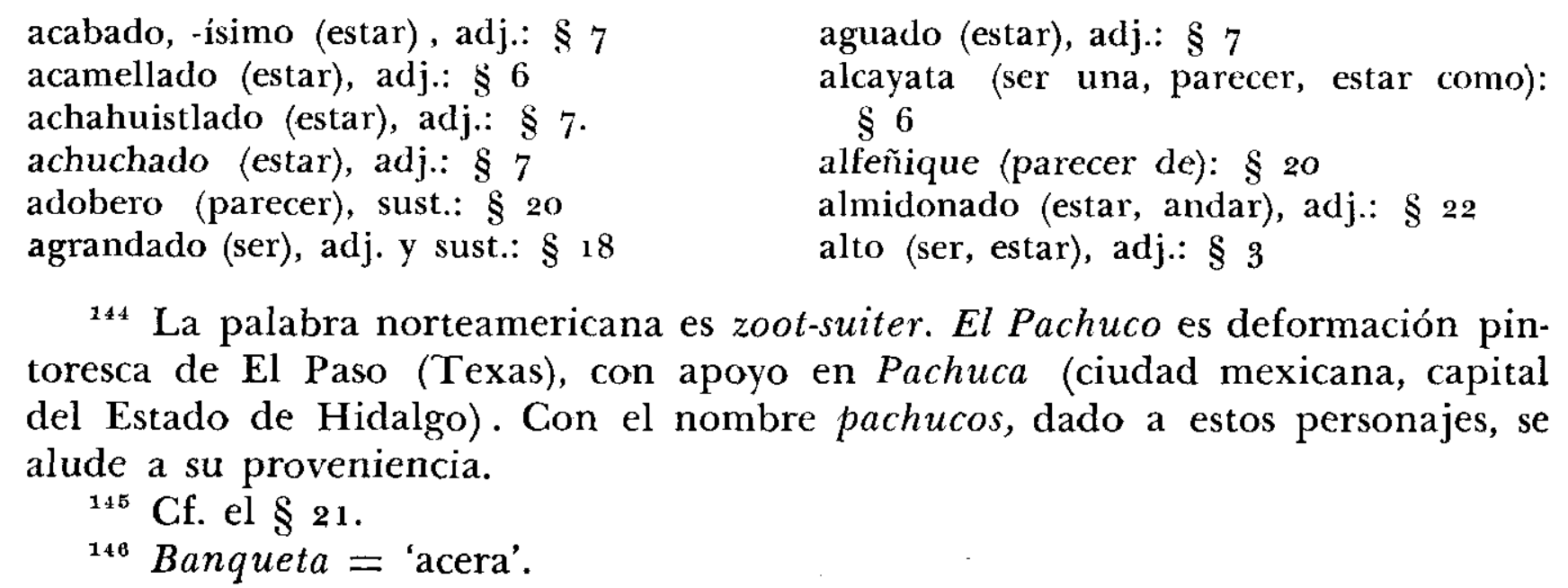


altote (ser, estar), adj. y sust.: $\$ 3$ andrajoso (ser, estar, andar), adj. y sust.: $\S 19$ anterior (estar ya), adj.: $\$ 16$ antiparro (ser), sust.: $\$ 11$ anuncio del paludismo (ser un): \$ 2 año de la calabaza (ser del): $\$ 17$ año de la canica (ser del): $\$ 17$ año de la caperuza (ser del): $\$ 17$ año de la hebra (ser del): $\$ 17$ año de la nañica (ser del): $\$ 17$ año de María Castaña (ser del): $\$ 17$ año del caldo (ser del): $\$ 17$ año del rey que rabió (ser del): $\$ 17$ apretado (ser), adj. y sust.: $\$ 23$

Aracuán (el): $\$ 10$ asqueroso (ser, estar, andar), adj. y sust.: $\$ 20$ atascado (ser, estar, andar), adj. y sust.: $\S 20$ atepocate (ser un): $\S 1$ azotar de elegante: §21

Bajos de Jalisco (ser de los): $§ 5$ barrigón (ser, estar), adj. y sust.: $\$ 4$ barrigón (al que es..., aunque lo fajen, etc.): $\$ 4$

barril (ser un): $\$ 4$

Beethoven (el): $\$ 10$

bien dado (estar), adj.: $\$ \$ 14,15$

bien plantado (ser, estar, andar), adj.: $\$ 21$

bien trajeado (ser, estar, andar), adj.: $\S \approx 1$ bigardón (estar, ser un), adj. y sust.: $\$ 3$

bigotes (ser de no malos): $\$ 14$ bigotes de aguacero (tener): $\$ 13$ bigotes pulqueros (tener): $\$ 13$ birrionda (ser, estar), adj. y sust.: $\$ 14$

bizco (ser, estar), adj. y sust.: $\S 11$

bizcocho 'bizco': \$ 11

bizcornete 'bizco': $\$ 11$

bizcorneto 'bizco': \$ 11

boca de alcancía (tener): $\$ 13$

boca de buzón (tener): $\$ 13$

boca de chancla (tener): $\$ 13$

boca de chiflido (tener): $\$ 13$

boca de garage (tener): $\$ 13$

boca de holán (tener): $\$ 13$

boca de nalgas de niño chiquito (tener): $\S 13$.

boca de quiupi (tener): $\$ 13$

boca de silbido (tener): $\$ 13$

boca de zaguán abierto (tener): $\$ 13$

boca (tener uno la...tan grande que se aconseja solo, etc.): $\$ 13$

bocón (ser), adj. y sust.: $\$ 13$.

Botijas (el): $\$ 13$

botijas (ser), adj. y sust.: $\S 4$

botijón (ser), adj. y sust.: $\$ 4$

buchona (ser), adj. y sust.: $\$ 4$ buena, -ísima, -ota (estar), adj.: \& 14

burro (ser un): $\S 14$

caballón (ser un): nota 83

caballona (ser), adj. y sust.: nota 83

caballote (ser un): $\S 14$

cabeza de alfiler (tener): $\S 9$

cabeza de alpiste (tener): $\$ 9$

cabeza de cerillo (tener): $\$ 10$

cabeza de escoba (tener): $\S 10$

cabeza de garbanzo (tener): $\S 9$

cabeza de jilote (tener): $\$ 10$

cabeza de medusa (tener): $\S 10$

cabeza de plumero (tener): $\$ 10$

cacarañado (estar), adj.: $\$ 9$

cacarizo (ser, estar), adj.: $\$ 9$

Cácaro (el): $\$ 9$

cachetón (ser, estar), adj.: $\S 9$

cachonda (ser, estar), adj. y sust.: $\S 14$ caerse (estar uno que se cae del árbol, etc.):

$$
\S 14
$$

caerse de elegante: $\$ 21$

caerse de mugroso: $\$ 20$

Calambres (el): $\$ 7$

calidad del tordo, etc. (ser de la): $\$ 4$

caliente (ser o estar), adj.: $\$ 14$

camello (estar), adj.: $\S 6$

campeona de natación (ser una): $§ 2$ cáncamo (ser, estar), adj. y sust.: $\S 16$ cáncano (ser, estar), adj. y sust.: $\$ 16$ canilla (tener): $\S 15$

canilludo (ser, estar), adj. y sust.: $\$ 15$ cara de caca llovida (tener): $\$ 9$

cara de coladera (tener): $\$ 9$

cara de chivo miado (tener): $\$ 20$

cara de choque (tener): $\$ 9$

cara de frontón (tener): $\$ 9$

cara de mierda llovida, etc. (tener): $\$ 9$

cara de palanqueta (tener): $\$ 9$

cara torteada (tener): $\S 9$

carbonero (parecer): $\$ 20$

carcamal (ser un): $\$ 16$

carcamán (ser un): $\$ 16$

cargador de la Merced (parecer): § 20

carrizo (estar como el): $\$ 7$

catrin (estar, andar), adj.: $\$ 21$

cegatón (ser, estar), adj. y sust.: $\$ 11$

centavo, -ito (ser un): $\$ 5$

Centímetro cúbico (el): $\$ 5$

ciego: $\$ 11$

cocerse (ya no se cuece de un hervor, etc.): $\$ 16$

coconete (ser un): $\$ \S 5,18$

cochambroso (ser, estar), adj. y sust.: $\S 20$

cochino (ser, estar), adj. y sust.: $\S 20$

cojo (ser, estar), adj. y sust.: $\S 8$

colgarse hasta la mano del metate: $\$ 22$

cola parada y almartigón (ir de): $\$ 22$

Colorado (el): $\S 10$

comino, -ito (ser un): $\S 5$ 
Copetes (el): $\S 10$

copetón (ser, estar), adj. y sust.: $\S 10$

copetón (ser), adj. y sust.: $\$ 23$

corcholata (ser una): $\$ 5$

correoso (ser, estar), adj. y sust.: $\S 15$

cosita (ser una): $\$ 14$

costal de huesos (ser un): $\$ 2$

cotorra (ser una): $\$ 16$

cotorrón, -ona (ser un, una): $\$ 16$

cuachalote, -ota (ser), adj.: $\$ \S 19,20$

cuadrado, -ote (ser, estar), adj.: $\S \S 5,15$

Cuadrado (el): $\$ 5$

de cuando amarraban perros con longaniza, etc. (ser): $\$ 17$

de cuando las viboras andaban paradas (ser): $\$ 17$

cuasimodo (parecer un): $\S 6$

cuatro lámparas (ser un): $\S$ il

cuatro mil para hoy (ser un): $\$ 11$

cuatro milpas (ser un): $\$ 11$

cuatro ojos (ser un): $\S 11$

cúcara (estar), adj.: $\$ 9$

Cúcara (el): § 9

cucaracho (estar), adj.: $\S 9$

cuco (estar, andar), adj.: $\$ 21$

cucho (ser), sust.: $\S 13$

cuero, -azo, -ito (ser un): $\S 14$

culebra guajira (ser una): $\$ 2$

culo (ser un, ser un buen): $\$ 14$

culo de gallina (parecer): $\$ 13$

cura (parecer): $\$ 13$

curro (estar o andar), adj.: $\$ 21$

cursi (ser), adj. y sust.: $\$ 22$

cutis de colegiala (tener): $§ 9$

chahuistle (caerle a uno el): $\$ 7$

chale (ser), sust.: $\$ 11$

chamacona (ser una): $\S 14$

chamagoso (ser, estar, andar), adj. y sust.: $\$ 20$

chancla (ser), adj.: $\$ 19$

changuita (ser una): $\$ 14$

Chapa, -o (el): $\$ 5$

chapaneco (ser, estar), adj.: $\S 5$

chaparrastroso 'zaparrastroso': $\$ 19$

chaparro (ser, estar), adj. y sust.: $\$ 5$

chaparrón (ser, estar), adj. y sust.: $\$ 5$

Chapis (el, la): $\$ 5$

chaquira, -ita (ser una): $\S 5$

Chaquira (la): \&5

charal (ser un, estar hecho un): § 2

charico (ser, estar), adj. y sust.: $\$ 2$

charrasqueado (estar, andar), adj.: $\$ 20$

charrasquiado 'charrasqueado': \& 20

charro (ser, estar, andar), adj.: $\S 22$

chato (ser, estar), adj. y sust.: $\$ 12$

chata narigata (ser una): $\S 12$

chico (era más ... el difunto): $\S 19$

chicharronero (parecer): $\S 20$

chiflido (ser o parecer un): \$2 chimuelo (ser, estar), adj. y sust.: $\S 13$

chinguiñoso (ser, estar), adj. y sust.: $\$$ ו

chino de no peinarse, etc. (estar): $\$ 10$

chipil, -ilón (estar), adj.: $\$ 7$

chipilingo (ser un): $\$ 18$

chipirristingo (ser un): $\$ 18$

chiquillo (ser, estar), adj. y sust.: $\S 18$

chiquirringo (ser un): $\$ 18$

chiquirristingo (ser un): $\$ 18$

chiras (hacer): $\$ 11$

chirrisco (ser), adj. y sust.: $\S 16$

chochear: $\S 16$

chocho (estar), adj.: $\S 16$

chorreado (estar, andar), adj.: $\$ 20$

chorriado 'chorreado': $\$ 20$

choteado (estar), adj.: $\$ 17$

chueca (tener... una tenaza): $\$ 8$

churriado (estar, andar), adj.: $\$ 20$

dejado (ser), adj. y sust.: $\$ 19$

delgado (ser, estar), adj. y sust.: $§ 2$

descuacharrangado (estar, andar), adj.: $\S$

19

descuajaringado (estar, andar), adj.: $\$ 7$

descuajeringado (estar, andar), adj.: $\$ 7$

desequilibrada (tener ... una tenaza): $\$ 8$

desgarranchado (estar, andar), adj.: $\$ 19$

desgreñado (ser, estar, andar), adj. y sust.:

$\S 10$

desgualichado (estar, andar), adj.: $\$ 19$

desguangado (estar), adj.: $\$ 7$

desguanguilado (estar, andar), adj.: $\$ \S$ 7,19

desguangüilado (estar, andar), adj.: $\$ \S$

7,19

desguanzado (estar), adj.: $\$ 7$

desguanzado (caminar), adv.: $\S 8$

desmangüilado (estar), adj.: $\$ 7$

desmechado (ser, estar, andar), adj. y sust.:

$\$ 10$

desmedrado (estar), adj.: $\S 7$

desmejorado (estar), adj.: $\$ 7$

desmirriado (ser, estar), adj. y sust.: $\$ 3$

desmolado (estar), adj.: $\$$ is

destorlongado (estar, andar), adj.: $\$ 19$

diente frío (ser): $\$ 13$

dientes de mula maicera (tener): $\$ 13$

dientón (ser, estar), adj. y sust.: $\$ 13$

doblado, -ote (estar), adj.: $\$ 15$

doble ancho (ser de): $\$ 15$

dulces meneos: $\$ 8$

Dumbo: $\$ 12$

duro (estar), adj.: $\$ 15$

echado a perder (estar): \$21

edad de la bicicleta (estar en la): $\S 18$

edad de la choca (estar en la): $\$ 18$

edad del pato (estar en la): $\S 18$

edad del plomo (estar en la): $\$ 18$

edad de la punzada (estar en la): $\$ 18$ 
elegantioso (estar, andar), adj.: § 21 Elena: $\S 5$ empaquetado (ser), adj. y sust.: $\S 23$ emperejilado (estar, andar), adj.: $\$ 22$ emperifollado (estar, andar), adj.: $§ 22$ emporcado (andar todo), adj.: $\$ 20$ empuercado 'emporcado': \$20 Enano (el): \&5 enano sietemesino (ser un): $\$ 6$ encanijado (ser, estar), adj. y sust.: $\$ 2$ encatrinado (estar, andar), adj.: $\$ 21$ enclenque (ser, estar), adj. y sust.: $\$ 2$ encolado (estar, andar), adj.: \$ 22 encopetado (ser), adj. y sust.: $\$ 23$ entacuchado (estar, andar), adj.: $\$ 22$ entecado (ser, estar), adj. y sust.: $\$ 2$ enteco (ser, estar), adj. y sust.: $\$ 2$ época (ser de la ... de), véase año de escandaloso (ser, estar, andar), adj.: $§ 22$ escoba vestida (ser una): $\S 2$ escuchimizado (estar), adj.: $\S 2$ escuintle (ser un): $\$ 18$

no escupir todavía en rueda: $\$ 18$ esmirriado (ser, estar), adj. y sust.: $\$ 3$ espantapájaros (parecer): $\$ 19$ espátula (ser una): $\S 2$ espiar (parecer estar espiando): § 19 espigado (ser, estar), adj. y sust.: $\S 3$ espiritifláutico (estar), adj.: $\$ 2$ esquelético (estar), adj.: $\$ 2$ esqueleto (ser un): $\$ 2$

esqueleto rumbero (ser un): $\$ 2$ estirado (ser), adj. y sust.: $\$ 23$ estropajo (andar como): $\$ 19$

fachas (estar 0 andar en): $§ 19$ fachoso (ser, estar, andar), adj. y sust.: $\S \S$ $19,21,22$

fachudo (estar, andar), adj.: $\$ 19$

faltarle a uno ponerse la mano del metate: $\S 22$

feo, -ísimo (ser, estar), adj. y sust.: $\S 1$

feo (no es que sea tan ... lo que pasa es, etc.): $\S 19$

feo con $F$ de ferrocarril (ser, estar): $\$ 1$ feo con $F$ de foco fundido (ser, estar): $\$ 1$ feo con $\mathrm{F}$ de fundillo, etc. (ser, estar): $\S 1$ feo (ser o estar más... que pegarle a Dios): $\$ 1$

feo (ser o estar más... que una noche oscura): $\$ 1$

feróstico (ser, estar), adj.: $\$ 1$

feto (ser un): $\$ 6$

fibra (ser un, una): $\$ 15$

fibrudo (ser, estar), adj. y sust.: $\$ 15$

fiero, -ísimo (ser, estar), adj.: $\S 1$

fierro (ser un): $\$ 14$

fifí (estar, andar), adj.: $\$ 22$

fifí (ser un): $\S 24$

fifí de barrio (ser un): $§ 24$ fifiriche (ser un): $\S 24$

fifirucho (ser un): $\S 24$

figuroso (ser), adj. y sust.: $\S 22$

flaco (ser, estar), adj. y sust.: $\S 2$

fluorescente (ser) : \& 10

fodongo (ser), adj. y sust.: $\$ \$ 4,19,20$

fodongón (ser, estar), adj. y sust.: $\$ \$ 4$, 20 fofo (estar), adj.: $\$ 7$

fondongona (ser, estar), adj. y sust.: $\$ 4$ fortachón (ser, estar), adj. y sust.: $§ 15$

forro, -azo, -ito (ser un): $\$ 14$

frenillo (tener): $\$ 13$

fundillo (ser un): $\$ 14$

Garrocha (la): §3

Garza (la): $\$ 8$

gato de azotea (paracer): $\$ 2$

gato espinado (caminar como): $\$ 8$

gigante, -ón (ser un): § 3

giro, -illo (andar), adj.: $\$ 21$

Glostora (el): \& 10

gorda (no es que sea $\tan \ldots$ etc.): $\$ 19$

gordinflón (ser, estar), adj. y sust.: $\$ 4$ gordo (ser, estar), adj. y sust.: $\$ 4$ grande (ser, estar), adj.: $\$ 16$

grande (era más... el difunto): $\$ 19$ grandote (ser, estar), adj. y sust.: $\S 3$ Greñas (el): $\S 10$ greñudo (ser, estar, andar), adj. y sust.: $\S 10$ guandajo, -ón (estar, andar), adj.: $\$ 19$ guangacho (estar, quedar), adj.: $\$ 19$ guango (estar), adj.: $\$ 7$ guango (estar, quedar), adj.: $§ 19$ güera (ser. . .a fuerzas): $\$$ in güera oxigenada (ser): $\$ 10$ gusano (ser un): $\$ 5$ gusto veneciano (tener su): $\S 4$

hablar gangoso: $\S 13$

hablar mocho: $\S 13$

hablar trabado: $\S 13$

hilachento (ser, estar, andar), adj.: $§ 19$ hilachiento 'hilachento': $\S 19$

hocicón (ser, estar), adj. y sust.: $\$ 13$ huevo de pípila (ser, parecer): $§ 9$

injerto de rifle y mango (ser un): $\$ 14$ Inmortal (el): $\$ 8$

inspector de azoteas, etc.: $\$ 3$

inspector de sótanos: $\$ 5$

ismirriado 'esmirriado': $\$ 3$

jamón (ser mucho... para dos huevos):

$\S 4$

jamona (ser, estar), adj. y sust.: $\$ 4$

jetón (ser, estar), adj. y sust.: $\$ 13$

jorobado (ser, estar), adj. y sust.: $\S 6$

jorobetas (ser un): $\S 6$

judas (estar hecho un, etc.): $\S 19$ 
kilométrico (ser, estar), adj.: $\S 3$

Kilómetro parado (el): $\$ 3$

labregón (ser un, estar), adj. y sust.: $\$ 3$ lacio (estar), adj.: $\$ 8$

lado (andar todo por ningún ...): $\$ 19$ ladrónde: $§ 21$

. lagañoso (ser, estar), adj.: §11

lagartón (ser, estar), adj. y sust.: $§ 16$

lamido (estar, andar), adj.: $\$ 22$

largotón (ser, estar), adj. y sust.: $\$ 3$

lazar (ya lo lazan): $\$ 10$

legañoso (ser, estar), adj.: \$ 1 I

lengua de hilacha (tener): $\$ 13$

lenteja, -ita (ser una): \$5

lentejas: $\$ 11$

lentejudo (ser), adj. y sust.: $\S 1$ ।

levitón y cola parada (ir de): $\S 22$

llanta (ser una): $\$ 4$

Llanta (la): $\S 4$

macaco (ser un): $\$ 1$

macicito (ya estar): $\S 16$

madre del aire (parecer la): $\$ 10$

mal fajado (estar, andar), adj.: $\$ 19$

manco (ser, estar), adj. y sust.: $\$ 8$

mangazo (ser un): $\$ 14$

mango (ser un, estar como, ser un real):

$\S \S 14,15$

mango de Manila (ser un): $\$ 14$

mano chula (ser): $\$ 8$

mano de gato (pasársele a uno la): $\$ 22$

mano de manivela (tener): $\S 8$

mano de tlapalería (pasársele a uno la):

$\S 22$

mano fría (ser): $\S 8$

mantecas (ser un): $\S 4$

Mantecas (el): $\S 4$

Mantecón (el): $\$ 4$

mantecoso (ser, estar, andar), adj. y sust.: $\S 20$

mantequillas (ser un): $\S 4$

Mantequillas (el): $\$ 4$

marras (ser de allá de cuando...): $\$ 17$

máscara (parecer): $\$ 22$

Mechas (el): § 10

mechas de alcalde viejo (tener): $\$ 10$

mechudo (ser, estar, andar), adj. y sust.:

$\$ 10$

Medio litro (el): $\$ 5$

Melenitas (el): $\$ 10$

qué me-le-notas: $\$ 10$

qué me-notas: $\$ 14$

mentadita (ser una): $\$ 5$

microbio (ser un): $\$ 5$

me mirabas: $\S 11$

mírame y no me toques (estar de): $\$ 2$

moco (ser un): $\S 18$

mocoso, -ito (ser un): $\S 18$ mocho (estar), adj.: \& 8

mofletudo (ser, estar), adj. y sust.: $\S 9$ molenque (ser, estar), adj. y sust.: $\$ 13$

momia (ser una vieja): $\S 2$

monumento (ser un): \$14

muchacho, -a en tecnicolor (ser un, una): $\S 10$

mugre (estar), adj.: $\S 20$

mugriento (ser, estar, andar), adj. y sust.:

$\S 20$

mugroso (ser, estar, andar), adj. y sust.:

$\$ 20$

mujerón (ser un): $\$ 14$

mula espiada (caminar como): $\$ 8$

nalgas de oso: $\S 4$

nalgón (ser, estar), adj. y sust.: $\S 4$

Narices (el): $\$ 12$

narices de alcanzaqueso (tener): $\$ 12$

narices de alcayata (tener): $\$ 12$

narices de huelepedos, etc. (tener): $\$ 12$

narices de hueso de mango (tener): $\$ 12$ narigón (ser, estar), adj. y sust.: $\S 12$ nariz, véase narices

narizón (ser, estar), adj. y sust.: $§ 12$

Narizotas (el): $\S 12$

nido de avispas (ser un, parecer): $\$ 9$

niño, -a bien (ser un, una): $\S 23$

niño, -a litri (ser un, una): $\$ 23$

niño, -a pera (ser un, una): $\$ 23$

ñango (ser, estar), adj. y sust.: $\S 2$ ñengo (ser, estar), adj. y sust.: $\S 2$

Ojitos (el): $\S 11$

ojos (írsele a uno los, etc.): $\$ 11$

ojos achalados (tener): $\$ 11$

ojos de apipizca dormilona (tener): $\S 11$

ojos de borrego ahorcado, etc. (tener): $\S 11$

ojos de pescado (tener): § 11

ojos de pingüica (tener): $\$ 11$

ojos de pulga pedorra (tener): $\S 11$

ojos de rajadura de alcancía (tener): $\$ 11$

ojos de rana (tener): $\$ 11$

ojos de rendija (tener): $\$ 11$

ojos de sapo (tener): $\$ 11$

ojos de toro loco (tener): $\$ 11$

ojos encontrados (tener): $\$ 11$

ojos estirados (tener): $\$ 11$

ojotón (ser), adj.: $\$ 11$

Ojotón (el): \$11

oler todavía a orines, etc.: $\$ 18$ orejas de papelote (tener): $\$ 12$ orejas de soplador (tener): $\$ 12$

pachiche (ser, estar), adj.: $\S 16$ pachichi (ser, estar), adj.: $\$ 16$ pachuco (ser un): $\$ 24$ pachuco de banqueta (ser un): $\S 24$ padrote (ser un), sust.: $§ \mathbf{2 4}$ 
padrote (estar, andar), adj.: $\$ 21$ padrotito de banqueta (ser un): $\$ 24$ pájara brava (parecer): $\S 10$ pajarito (ser un): $\$ 8$ palillo (ser, parecer, estar hecho un): $\$ 2$ Palmolive (el): $\$ 9$ palo (ser un): $\$ 12$

palo ensebado (¿dónde hubo...?): $\$ 21$ Pancho (don): $\$ 4$ pantalón de brincacharcos: $\$ 19$ panza (dejarse la): $\$ 4$

Panza (el): \$4 panza de pulquero (tener): $\$ 4$ panza de tambora (tener): $\$ 4$ panzón (ser, estar), adj. y sust.: $\$ 4$ panzón (al que es..., aunque lo fajen, etc.): $\$ 4$ paquetudo (ser), adj. y sust.: $\$ 23$ -pariente de los topos (ser): $\$ 11$ pariente del suelo (ser): $\$ 5$ pasita (ser una): $\$ 16$ pata chueca (ser): $\$ 8$ pata chula (ser): $\$ 8$ pata de ala (ser): $\$ 8$ pata de ángel (ser): $\$ 8$ pata fría (ser): $\$ 8$

Patas chulas $(\mathrm{el}): \& 8$ patas de alambre (tener): $\$ 8$ patas de chorro de atole, etc. (tener): $\$ 8$. patas de popote (tener): $\$ 8$ pato, -azo (ser un): $\$ 14$ pato (caminar como): $\$ 8$ pato asustado, etc. (caminar como): $\$ 8$ patuleco (ser, estar), adj. y sust.: $\$ 8$ pedazo de retazo de hombre (ser un) $: \$ 5$ pegarse en las vigas: $\$ 16$ peinarse (no más se peinó y se vino): $\$ 10$ peladote (ser un): $\$ 15$ pelea pasada (ser de la): $\$ 17$

peor (no estar tan): $\$ 14$ pepenador (parecer): $\$ 20$ Percha (la): $\$ 3$

perfil (si se pone de ..., no se ve, etc.): $\$ 2$ perico (caminar como): $\$ 8$

perico en alfombra, etc. (caminar como): $\S 8$

peripuesto (estar, andar), adj.: $\S 21$ perita en dulce (ser una): $\$ 14$ Pescado (el): $\$$ I

petacas (para ... las mías): $\$ 4$ petacón (ser, estar), adj. y sust.: $\$ 4$ picado (estar), adj.: $\$ 9$

piernas de alambre (tener): $\$ 8$ piernas de chorro de atole, etc. (tener): $\S 8$

piernas de popote (tener): $\$ 8$ pingajoso (estar, andar), adj.: $\S 19$ pingüica (ser una): $\$ 18$ piojo (ser un): $\S 5$ pipa, anteojos y cola amarrada (ir de): $\S 22$

pipa, guante y bastón (ir de): $\$ 22$ pipa y anteojos (ir de): $\$ 22$ pirinola (ser una): $\$ 18$ pirruña (ser una): $\$ 18$ pistiojo (ser), adj.: \& 11 pitañoso (ser, estar), adj.: $\S 11$ planchado (estar, andar), adj.: § 21 plantado (estar, andar), adj.: \$2 I

Plumero (el): \$10

Poca luz (el): $\$$ i1

pollo en tendedero (caminar como): $\$ 8$ pollo espinado, etc. (caminar como): $\$ 3$ pomada (ir de mucha): $\$ 22$

pomadoso (ser), adj. y sust.: $\$ 22$

ponchada (traer... una llanta): $\$ 8$

ponchadito (estar), adj.: $\$ 5$

ponchado (estar), adj.: $\$ 7$

popoff (ser), adj.: $\S 23$

prendido (estar, andar), adj.: §21

problema (no tener... para ver un parti do de tenis): $\$ 11$

puerco (ser, estar), adj. y sust.: $\$ 20$

pulga (ser una): $\S 5$

pulquero (parecer): $\$ 4$

Punto y coma (el): $\$ 16$

quedada (ser una): $\S 16$

quedarse para vestir santos: $\S 16$

queque (ser), sust.: $\$ 13$

quintopatiero (ser un): $§ 24$

rabón (ser, estar, andar), adj.: $§ 19$

Rana (la): $\S 11$

rascar (ni rascándole el lomo): $§ 16$

rebuena (estar), adj.: \$ 14

reintegro (ser un): $\$ 5$

relamido (ser), adj. y sust.: $\S 22$

renco (ser, estar), adj. y sust.: $\$ 8$

rifle (ser un, estar como), sust.: $\$ \S 14,15$

róido (estar), adj.: $\$ 9$

rotinfacio (ser un): $\$ 24$

roto, -a, -ito, -ita (ser un, una): $\S 24$

rucano, -ito (ser, estar), adj. y sust.: $\$ 16$

ruco, -ito (ser, estar), adj. y sust.: $\$ 16$

sacudir techos (ocupar a alguien para): $\$ 3$

Sapo (el): § 11

sazona (estar), adj.: $\$ 14$

sebosa (ser una vieja): $\$ 4$

semáforo: $\$ \S 10,11$

señorita quedada (ser una): $§ 16$

señorita recortada (parecer): $\$ 18$ solterón, -ona (ser un, una): \$ 16 sope del perro (ser el): $\$ 18$ sordeleque (ser, estar), adj. y sust.: $\S 12$ sordo como una tapia (estar): $\$ 12$ soreco (ser, estar), adj. y sust.: $\S 12$ soreque (ser, estar), adj. y sust.: $\S 12$ 
sotaco (ser un): $\S 5$

sucio (ser, estar), adj. y sust.: $\$ 20$

tabla vestida (ser una): $\S 2$

tachuela (ser una): \$5

tapia (ser una): $\$ 12$

tapón (ser un): $\$ 5$

tapón de alberca (ser un): $\$ 5$

taquete (ser un): $\S 5$

tartajoso (ser), adj. y sust.: $\$ 13$

tartamudo (ser), adj. y sust.: $\S 19$

tarzán (ser un): $§ 24$

teleque (ser, estar), adj. y sust.: $\$ 16$

tembeleque (ser, estar), adj. y sust.: $\$ \$ 7,16$

Temblores (el): $\$ 7$

tencua (ser), sust.: $\$ 13$

tepocate (ser un): $\$ 1$

terror de la peluquería (ser): $\$ 10$

tiempos de don Porfirio (ser de): $\$ 17$

tilico (ser, estar), adj. y sust.: $\$ 2$

timbón (ser, estar), adj. y sust.: $\$ 4$

tipo, -azo (ser un): $\$ 15$

tlapalería (parecer): $\$ 22$

tonel (ser un): $\$ 4$

toni (ser un): $\$ 4$

tonina (ser una): $\S 4$

toro, -azo, -ote (ser un): $\$ 15$

trabado (estar), adj.: $\S 15$

trajeado (estar, andar), adj.: $\$ 21$

trapo de sacudir (estar o andar como): $\S 19$

trillado (estar), adj.: $\$ 17$

tripón, -udo (ser, estar), adj. y sust.: $\$ 4$

trompa de hule (tener): $\$ 13$

Trompas (el): $\S 13$

Trompitas (el): $\$ 13$ trompudo (ser, estar), adj. y sust.: $\$ 13$

tronar (está pa' tronarle los huesitos): $\S 14$

vejancón (ser un): $\$ 16$

vejarano (ser, estar), adj. y sust.: $\$ 16$

vetarro (ser, estar), adj. y sust.: $\$ 16$

veterano (ser, estar), adj. y sust.: $\$ 16$

viejano (ser, estar), adj. y sust.: $\$ 16$

viejo (ser, estar), adj. y sust.: $\$ 16$

viejo (ser más... que el atole): $\$ 17$

viejo (ser más ... que la roña): $\$ 17$

viejo (ser más... que Matusalén): $§ 17$

viejo birriondo (ser un): $\$ 16$

viejo cachondo (ser un): $\$ 10$

viejo caliente (ser un): $\$ 16$

viejo cáscara (ser un): $\$ 16$

viejo chirrisco: véase chirrisco

viejo lagartón: víase lagartón

viejo rabo verde (ser un): $\$ 16$

viejón (ser un): $\$ 14$

viejorrón (ser un): \$14

viernes (estar), adj: $\$ 16$

virolo (estar), adj.: \$11

visionudo (ser), adj. y sust.: $\$ 22$

vitrinas (estar), adj.: \$ II

vizconde 'bizco': \$ 11

Vizconde de Mirachueco: \$11

volar (estar uno que vuela, ya vuela): $\$ 2$

xocoyote (ser el): $\$ 18$

xongo (ser, estar, andar), adj. y sust.: $\$ 19$

zancón (estar, andar), adj.: $\$ \$$ 3, 19

zaparrastroso (ser, estar, andar), adj. y

sust.: $\$ 19$

zarrapastroso (ser, estar, andar), adj. y

sust.: \$ 19 